\title{
TÁCITO E O IMPÉRIO ROMANO
}

Fábio Duarte Joly

Professor adjunto de História Antiga e Medieval na Universidade Federal do

Recôncavo da Bahia e membro do Laboratório de Estudos sobre o Império Romano (LEIR)

\section{Resumo}

A fortuna de Cornélio Tácito no pensamento político europeu demonstra a intensidade da recepção de sua obra nos debates sobre a natureza do poder monárquico e estratégias aristocráticas de ação na corte imperial. Nesse sentido, do século XVI ao século XIX, Tácito foi muitas vezes tomado como um contemporâneo, num diálogo entre presente e passado, de acordo com uma noção de história entendida como magistra vitae. A bibliografia moderna sobre Tácito, de certa forma, ainda se mantém nessa trilha ao enfatizar, como objeto de estudo, primordialmente as representações taciteanas dos imperadores, de Augusto a Nero. Pretende-se, nesta comunicação, ampliar o foco de discussão, indagando-se sobre o próprio conceito de império na obra de Tácito, visando apontar os elementos sublinhados pelo historiador latino como responsáveis pela manutenção do império de Roma, a despeito dos conflitos sociopolíticos internos. 
O presente texto apresenta possibilidades de pesquisa sobre o Império Romano a partir dos conceitos de ordem imperial e fronteiras internas, propostos como eixos norteadores de reflexões do Laboratório de Estudos sobre o Império Romano (LEIR). Meu interesse é discutir como o estudo de Tácito pode contribuir para um entendimento das múltiplas identidades operantes no Império Romano, as fronteiras estabelecidas entre elas, e como essas se articulavam para a constituição de uma "ordem imperial”.

O tema das identidades está particularmente em voga na historiografia mais recente sobre o Império Romano. Conceitos como "romanização” e "helenização” estão sendo revistos e não mais tomados como sinônimos de identidades fixas e imutáveis, impostas a populações sob influência da cultura grega e romana. O esforço agora é pensar como diferentes identidades coexistiam, sem excluir-se, como no caso de identidades "locais" que se expressaram ao longo de toda a duração do Império Romano. Nesse sentido, tende-se a adotar uma perspectiva de conceber as identidades como relacionais e variáveis, vinculadas aos interesses e objetivos dos indivíduos no espaço e no tempo. Contudo, mesmo com o reconhecimento dessa variabilidade, ainda persiste o entendimento de que uma identidade prevaleça e contribua para a constituição de uma ordem. Veja, por exemplo, a conclusão a que chega Andrew Wallace-Hadrill, em seu último livro, Rome's cultural revolution:

A identidade cultural romana era fortemente contestada no período republicano, na medida em que a identidade do corpo cidadão, e a distribuição do poder no seu interior, também era contestada. Augusto, ao obter um tipo de consenso, que permitiu a contínua expansão do corpo cidadão, e a contínua penetração da elite a partir das margens, foi capaz de estabelecer uma forma de consenso sobre como os romanos deveriam ser ou se comportar, como suas cidades seriam e quais costumes e rituais seguiriam. ${ }^{1}$

Em síntese, subentende-se que o imperador gera um consenso que possibilita uma identidade coletiva aparentemente não conflituosa, instaurando uma ordem. Essa interpretação moderna não deixa de estar inspirada na visão dos próprios antigos sobre a origem do Principado. Sobretudo Tácito equaciona esse regime à estabilidade, ao operar uma articulação entre domus imperial e res publica, no sentido de que, no Principado, uma identidade corporativa, tanto do Senado,

\footnotetext{
${ }^{1}$ Rome's cultural revolution. Cambridge: Cambridge University Press, 2008, p. 453-454.
} 
quanto da plebe e dos exércitos, estabeleceu-se a partir da vinculação com a casa imperial, proporcionando um consenso e estabilidade.

Mas, para o autor latino, o resultado último dessa configuração política poderia colocar em risco a expansão e manutenção do Império, visto que, em geral, Tácito advoga um estado constante de conflito para preservar esse Império. ${ }^{2}$ Essa tensão permeia sua narrativa e pretendo abordá-la aqui principalmente com referências ao livro I dos Anais, que trata do fim do reinado de Augusto e primeiros anos de Tibério.

Em primeiro lugar, então, cabe perguntar: o que era o Império para Tácito? Um aspecto a ser relevado é o limite de sua visão sobre o Império de Roma. Lemos no alentado e referencial estudo de Ronald Syme que, para esse historiador-senador, o tema central consistia nas relações pessoais do imperador com senadores e governadores, e não na condição geral das cidades, povos e províncias sob o domínio romano. Nos Anais, Tácito não comenta como as finanças e as rendas públicas eram geridas, e tampouco a agricultura, o comércio e as manufaturas no Império. Tampouco a situação das camadas populares na cidade e no campo chama sua atenção. Para Syme, o objeto de Tácito é o governo romano que, por sua vez, se concerne apenas com a classe senatorial e exércitos. As províncias pouco aparecem em sua narrativa por serem "privadas de identidade”. Portanto, a visão taciteana apresentar-se-ia mais urbana, centrada em Roma, do que propriamente imperial. ${ }^{3}$

Na mesma linha de Syme, Fergus Millar assinala que, nos Anais, a narrativa dos eventos em Roma é construída, em grande parte, por uma série de cenas no Senado, a ponto de essa ótica relegar à sombra o fato de que a história de Roma no Império, assim como na República, deveria ser a história de toda uma comunidade, da res publica entendida como uma comunidade de cidadãos, e não apenas da relação entre Senado e imperadores em Roma. ${ }^{4}$

Essa perspectiva circunscrita não deixa de estar explicitada no proêmio dos Anais quando Tácito inicia afirmando que "a princípio foram reis os que governaram a cidade de Roma” (Urbem Romam a principio reges habuere, Ann., I, 1) e depois anuncia que tratará "de Augusto pouco e seu fim, e depois o principado de

\footnotetext{
${ }^{2}$.BENARIO, H. W. Tacitus'view of the Empire and the pax romana. In:ANRW, II.33, 5, 1991, p. 3.349.

${ }^{3}$ SYME, R. Tacitus. Oxford: Oxford University Press, 1967, p. 443-445.

${ }^{4}$ MILLAR, F. The Roman city-state under the emperors, 29 BC-AD 69. Prudentia, supplementary number, 1998, p. 115.
} 
Tibério e os seguintes” (pauca de Augusto et extrema tradere, mox Tiberii principatum et cetera, Ann., I, 2). Seu foco é, portanto, o Principado, e baseado em Roma.

Na introdução das Histórias, obra anterior aos Anais e que narra as guerras civis após a morte de Nero em 68 d.C., embora Tácito demonstre maior preocupação em descrever o quadro provincial, Roma permanece como centro de referência. Propõe-se a descrever a "situação da cidade, o pensamento dos exércitos e a atitude dos provinciais" (repetendum videtur qualis status urbis, quae mens exercituum, quis habitus provinciarum, Hist., I, 4). No entanto, são os exércitos estacionados nas províncias que lhe interessam, e na medida em que podem influenciar a lutar por um poder que, ao final das contas, deveria ser exercido em Roma. ${ }^{5}$ Se o ocaso da dinastia Júlio-Cláudia desvelara um dos arcana imperii - de que um imperador poderia ser feito fora de Roma (Hist., I, 4) - é, contudo, da urbs que o princeps governará o Império.

Do ponto de vista formal, essa centralidade de Roma também decorre de uma característica de sua narrativa nos Anais: a abordagem cronológica dividida por anos, retomando uma tradição analista que introduzia o começo de cada ano com os nomes dos dois cônsules ordinários. Todavia, isso não significa que Tácito praticasse a história analista tradicional, à maneira dos antigos anais pontificais ou da narrativa de Tito Lívio. Adota antes a forma dessa história no sentido de que toma como parâmetro uma estrutura discursiva, associada ao passado republicano, para escrever sobre o Principado. ${ }^{6}$

O contraste entre passado republicano e presente imperial é constantemente acionado por Tácito, em especial quando trata da escrita da história. Nos Anais, em uma digressão, ressalta que, para os antigos escritores, estavam à disposição "grandes guerras, reis abatidos e capturados, (...) discórdias entre cônsules e tribunos, leis agrárias e frumentárias, disputas entre a plebe e os principais cidadãos”, enquanto, no Principado, predominava "uma paz imóvel e moderadamente estimulada, fatos tristes na cidade e um imperador [Tibério] que era indiferente quanto a alargar o império” (IV, 32). Tácito expressaria assim uma visão de mundo agonística, em que o conflito interno e externo aparece como necessário para a expansão do Império de Roma.

\footnotetext{
${ }^{5}$ MARTIN, R. Tacitus. London: Bristol Classical Press, 1989, p. 70. Prevalece na obra de Tácito um olhar voltado para as províncias ocidentais do Império (Espanha, Bretanha e Gália) (cf. GRIMAL, P. Tacite. Paris: Fayard, 1990, p. 44) e predominantemente retratadas sob um viés militar (GASCOU, J. Tacite et les provinces. In: ANRW, II.33, 4, 1991, p. 3.463).

${ }^{6}$ GINSBURG, J. Tradition and theme in the Annals of Tacitus. New Hampshire: Ayer, 1984, p. 100.
} 
A associação entre Principado e paz - que aparece como um contraponto a esse ideal - é trabalhada por Tácito já a partir do proêmio dos Anais, quando oferece ao leitor uma sequência progressiva de acontecimentos que antecederam o estabelecimento do regime imperial. Inicia com os reis e encerra com a ascensão de Augusto que, nas suas palavras, "tudo aceitou sob um império, com o nome de príncipe, cansados que estavam todos das discórdias civis” (qui cuncta discordiis ciuilibus fessa nomine principis sub imperium accepit, Ann., I, 1). Frase sintética, mas que comporta uma dupla interpretação, se aceitarmos a leitura de A. Neschke, para quem a sintaxe latina também pode significar que Augusto aceitou, sob um imperium, todos aqueles fatigados pelas guerras civis. ${ }^{7}$ Nesse caso, Augusto se equipararia aos antigos reis de Roma que tinham nas mãos a cidade e, por conseguinte, seus grupos sociais.

A identidade desses grupos começa a se delinear quando Tácito expõe a seguir as bases de apoio de Augusto. Escreve: “Quando seduziu (pellexit) os soldados com donativos, o povo com trigo, e a todos (cunctos) com a doçura da paz, começou a elevar-se aos poucos, trazendo a si os deveres do Senado, as magistraturas e as leis, sem encontrar adversário” (Ann., I, 2). A ausência de oposição ao princeps é explicada, para o caso dos nobres (nobiles), como resultado de um comportamento servil, que visava mais as benesses do presente (honras e riquezas) do que as turbulências do passado. As províncias, por sua vez, também não se opuseram, visto a desconfiança que votavam ao governo do Senado e do povo romano (suspecto senatus populique imperio). Ao se referir à ascensão de Tibério, os mesmos elementos voltam a recorrer: "Em Roma cônsules, senadores e cavaleiros lançavam-se à escravidão (ruere in servitium)”, seguidos pelos prefeitos do pretório e da anona, e do Senado, exército e povo (senatus milesque et populus, Ann., I, 7).

Além desses grupos de sustentação, diz Tácito que a atribuição de cargos honoríficos a membros da casa imperial por Augusto foi um elemento de consolidação de sua dominação (subsidia dominationi), pois garantiu a transmissão do poder imperial, que agora dependia de uma integra domus (I, 3). Com a morte da maioria dos possíveis sucessores de Augusto, restou Tibério, "para

\footnotetext{
${ }^{7}$ Nesse último caso, cuncta não é apenas complemento do objeto direto de accepit, mas também sujeito de fessa. Cf. NESCHKE, A. Le prologue des Annales de Tacite: analyse structurale et interprétation de texte. Les Études Classiques, 46, 1978, p. 45-61. Para cuncta no sentido de um conjunto de poderes, ver WOODMAN, A. J. Tacitus on Tiberius' accession. In: WOODMAN, A. J. Tacitus reviewed. Oxford: Clarendon Press, 1998, p. 66.
} 
quem tudo convergiu” (illuc cuncta vergere). Tácito interpreta essa nova configuração do poder como uma reviravolta no estado da cidade, o abandono dos costumes antigos e íntegros (Igitur verso civitatis statu nihil usquam prisci et integri moris, I, 4), já que doravante a estabilidade e a paz estariam associadas à composição da casa reinante.

Esse aspecto também é expresso quando Tácito apresenta as avaliações positivas do reinado de Augusto: "O Oceano e os rios distantes foram as barreiras que deu ao império; legiões, províncias, esquadras, tudo estava conectado (cuncta inter se conexa); prevalecia o direito frente aos cidadãos, a moderação com os aliados; a própria cidade foi magnificamente ornada; se tratou poucas coisas com severidade, foi para assegurar a paz” (I, 9). Na versão que Tácito fornece, no livro XI dos Anais, do discurso de Cláudio, favorável ao ingresso de nobres gauleses no Senado, percebe-se igual ênfase na integração do Império: "Quando se consolidou a paz interna (solida domi quies) e contra adversidades externas prevalecemos, quando os Transpadanos foram admitidos na cidade, quando sob pretexto que nossas legiões espraiaram-se por todo o orbe, nós incorporamos os mais vigorosos dentre os provinciais, remediando o enfraquecimento do império" (XI, 24).

A principal diferença entre o discurso apresentado por Tácito e o texto original preservado em uma inscrição ${ }^{8}$ reside no fato de o historiador utilizar um episódio particular - a concessão de privilégios a um grupo restrito das aristocracias provinciais, oriundas da Gália Comata - para avançar uma lei geral de que a sobrevivência do Império dependeria da absorção de elementos externos a Roma e a Itália. ${ }^{9}$

Logo, nesse primeiro momento, imperium significa um poder exercido pelo princeps, e antes dele pelo Senado e pelo povo. Imperium, no Principado, está associado à ordem, enquanto na República é instrumento de conflito e disputa cujos reflexos atingem Roma e suas províncias. No regime imperial, pela ótica de Tácito, ocorreria como que uma privatização da res publica, em que prevaleceriam as relações diretas com o imperador da parte do Senado, povo e exército. O emprego da metáfora da escravidão é um elemento ilustrativo desse contexto e presente não só na obra de Tácito. Finda a República, a escravidão situou-se no centro de uma negociação discursiva entre princeps e aristocracia

\footnotetext{
${ }^{8}$ CIL XIII, $1668=$ ILS 212.

${ }^{9}$ GRIFFIN, M. T. The Lyons Tablet and Tacitean hindsight. Classical Quarterly, 32, 1982, p. 413.
} 
no contexto de uma adaptação das instituições republicanas e dos códigos de conduta aristocráticos à presença de um imperador. Se, por um lado, a relação senhor-escravo representaria um modelo negativo de interação entre imperador e aristocracia - devido às conotações negativas de servitus e seus $\operatorname{cognatos}^{10}$-, por outro lado, em Tácito, tal relação não deixa de ter um conteúdo implícito positivo, no sentido de se constituir em componente da ordem imperial. A escravidão, ao caracterizar um comportamento voluntário de adequação ao novo regime, proporciona um consenso.

Tácito acaba assim por corroborar uma nova cultura política, cuja estruturação discursiva substituiu um modelo centrado na res publica por outro baseado na casa imperial. Essa transformação aparece explicitamente em decretos senatoriais da época de Tibério, como a Tabula Siarensis, de 19 d.C., a Tabula Hebana, de 20 d.C., e o senatus consultum de Cn. Pisone patre, de 23 d.C., em que as duas primeiras testemunham honras conferidas pelo Senado a Germânico, enquanto o senatus consultum trata da condenação de Cneu Piso, acusado de assassiná-lo.

Esses decretos revelam que o Senado desempenhou um papel primordial na transmissão da nova ideologia, em especial de transições da família imperial, e, ao fazê-lo, ganhou nova visibilidade na Itália e mesmo usurpou funções legislativas ao decretar honras antes de serem outorgadas por lei. ${ }^{11} \mathrm{O}$ comportamento que Tácito qualifica de servilismo ou adulação representa essa estratégia senatorial de vincular o Senado à casa imperial, conferindo nova identidade aos membros desse órgão. Nos Anais, isso é observável, por exemplo, quando o historiador relata pedidos de senadores para que se atribuam honrarias a membros da família imperial, como a Augusta, mãe de Tibério (I, 14).

Assim como o Senado é retratado como diretamente vinculado à domus Caesaris, o mesmo Tácito procura fazer com os exércitos estacionados nas províncias, embora não com muito êxito. Isso é exemplificado, ainda no livro I dos Anais, quando da narrativa da revolta das legiões da Panônia (I, 16-30) em 14 d.C. Na ocasião, Tibério enviou, para tratar com os sediciosos, seu filho Druso, acompanhado de senadores (cum primoribus ciuitatis). ${ }^{12} \mathrm{O}$ centurião, representante das legiões reunidas em assembleia (contio), manifestou-se contra

\footnotetext{
${ }^{10}$ ROLLER, M. Constructing autocracy: aristocrats and emperors in Julio-Claudian Rome. Princeton: Princeton University Press, 2001, p. 227.

${ }^{11}$ ROWE, G. Princes and political cultures: The new Tiberian senatorial decrees. Ann Arbor: The University of Michigan Press, 2002, p. 64-66.

${ }^{12}$ Cf. Ann., I, 11, para esse termo com referência a senadores.
} 
a posição do imperador, divulgada por Druso, em remeter ao Senado os favores e castigos que deveriam ser impostos às tropas. Exigia, pelo contrário, uma intervenção direta do representante da família imperial. O interessante de se observar no relato taciteano é a solução oferecida para o impasse promovido pelo questionamento à autoridade imperial. Um eclipse da lua fez com que os soldados o interpretassem como reflexo e resultado de suas ações, levando-os a restaurar pelas próprias mãos a disciplina militar (I, 28). A ordem nas legiões é assimilada às leis do cosmos, como se os mundos natural e divino revolvessem por conta da rebelião das tropas. ${ }^{13}$

A mensagem subliminar do texto de Tácito é que não há uma vinculação totalmente harmônica entre o exército nas províncias e o princeps. Se as tropas estacionadas em Roma enquadram-se na lógica da privatização da res publica, aquelas provinciais mostram-se recalcitrantes. Não é à toa que o termo contio aparece com frequência nas descrições de revoltas militares por Tácito. Embora a cultura política do exército seja fundada na hierarquia e disciplina, a interação entre tropas e comandantes ocorre em contiones, em assembleias onde se empregavam oratória e o princípio da decisão coletiva. ${ }^{14}$ Se nos voltarmos para o povo de Roma, a persistência da cultura política das assembleias também se revela. Embora Tácito mencione que os comícios foram transferidos, sob Tibério, do Campo de Marte para o Senado, ressalta que subsistiram alguns que reuniam as tribos da cidade e, portanto, fora do “arbítrio do príncipe” (I, 15).

Esses dados indicam que, se Tácito tem uma visão da sociedade de Roma como ordenada em torno da casa imperial, as esferas de deliberação do Senado, povo e exército aparecem preservadas, ainda que minimizadas em sua narrativa, já que ele vê toda a ação nesses espaços como uma imagem de liberdade, uma forma sem conteúdo. Contudo, enquanto Tácito confere pouco relevo aos espaços de deliberação coletiva, o mesmo não ocorre quando se trata da ação de viri militares nas províncias do Império. O exemplo mais emblemático é o de seu próprio sogro, Júlio Agrícola.

A carreira inicial de Agrícola na Bretanha é mostrada por Tácito com o intuito de afirmar que o correto funcionamento do Império dependia de uma competição intraelite por glória. Como recentemente argumentou Dylan Sailor,

\footnotetext{
${ }^{13}$ O'GORMAN, E. Irony and misreading in the Annals of Tacitus. Cambridge: Cambridge University Press, 2000, p. 31.

${ }^{14}$ ROWE, op. cit., p. 163.
} 
Tácito "a fim de demonstrar como deveria operar a economia da glória, (...) caracterizou a Bretanha como um espaço separado do restante do Império, como um campo para a atividade da elite isolado da influência do princeps em Roma e do sistema cultural e político organizado em torno de principes" ${ }^{15}$ Nesse sentido, o Império configura-se como um processo constantemente autorrenovável de expansão, se movido por indivíduos que buscam afirmar-se pela glória militar, mas sem descartar a existência de uma hierarquia. Caso esta não encontre vazão no regime imperial, ao despertar a hostilidade do imperador, os esforços dessa elite serão frustrados e a manutenção do Império comprometida.

É também o modelo que advoga em sua obra de cunho etnográfico, a Germânia, em que descreve como princípio motor do comitatus a disputa entre os guerreiros por prestígio perante o chefe. Este, por seu turno, serve-se do seu séquito para rivalizar em prestígio com os demais chefes. No campo de batalha, segundo Tácito, é a emulação mútua entre comandantes e comandados que impera. O chefe (princeps) é o centro da comunidade guerreira germânica. Ele fornece o padrão de conduta para seus subordinados e estes combatem, não visando uma glória pessoal, mas a glória do chefe. A este cabem os méritos da vitória. Em contrapartida, os guerreiros exigem demonstrações de liberalidade (liberalitas) do chefe.

A conduta de Agrícola diante de seus superiores - de emulação positiva, mas sem rompimento da hierarquia - é aquela que Tácito transplanta para a sociedade germânica, anulando assim as fronteiras étnicas, sociais e políticas entre romanos e germanos. Em suma, trata-se mais de identidade do que de alteridade, pois, como ressaltou Erwin Wolff, o comitatus, como representado por Tácito na Germânia, é uma organização romana, embora não exatamente igual, mas semelhante. ${ }^{16}$

Esse jogo de identificação entre grupos díspares é o que também vemos operando quando recorre à metáfora da escravidão, pois servitus é a submissão dos senadores e cavaleiros em Roma diante do imperador, dos soldados romanos a seus superiores e de alguns chefes bárbaros com relação a Roma. Ao afirmar que todos são "escravos", dilui as identidades específicas de cada grupo, traçando uma identidade única cuja referência é a subordinação ao imperador. O próprio historiador, nos Anais, chega a afirmar que a vinculação pessoal ao

\footnotetext{
${ }^{15}$ SAYLOR, D. Writing and Empire in Tacitus. Cambridge: Cambridge University Press, 2008, p. 73.

${ }^{16}$ WOLFF, E. Das geschichtliche Verstehen in Tacitus Germania. Hermes, 69, 1934, p. 128.
} 
imperador e a prática de emulá-lo era comum dentre os “homens novos” que progressivamente adentravam na política romana:

Homens novos, procedentes dos municípios e colônias e até mesmo das províncias, foram admitidos no Senado e introduziram a parcimônia a que estavam afeitos; e ainda que alguns tivessem sorte ou habilidade para atingir uma abastada velhice conservaram o mesmo gênero de vida. Foi, no entanto, Vespasiano quem deu impulso a essa severidade de costumes, vivendo ele mesmo ao antigo modo de vestuário e mesa. O desejo de agradar e imitar o príncipe fez mais que qualquer lei coercitiva ou medo de punição (Ann., 3, 55).

É esta subordinação ao princeps que, em última instância, encerra a visão de Tácito sobre o Império Romano e que não deixa de ser caracterizada por uma ambiguidade: a presença do imperador é necessária para um tipo de ordem, que diminui ou elimina o conflito entre grupos políticos, mas a ausência de um imperador permitiria outra forma de estabilidade, que incorpora o conflito. No primeiro caso, Tácito tem em mente a situação em Roma, focando o Senado, mas também o povo da cidade. O cerceamento da liberdade política desses grupos, entendida como espaço de deliberação e disputa, é equacionado a uma ordem constituída pela ligação de Senado e povo à casa imperial. No segundo caso, o historiador volta-se para o Império e sua preservação pela força das armas, e, portanto, salienta a necessidade de chefes militares cuja ação, e resultante glória conquistada, não pode ser coibida pelo princeps. Ou seja, pressupõe a importância do conflito entre grupos ou no interior dos mesmos, em que cada indivíduo faz valer a sua libertas.

Tácito apresenta a identidade corporativa do Senado, povo e exército, atrelando-a a casa imperial e postulando, dessa maneira, uma alternativa para manter a estabilidade do Império. Por outro lado, igualmente revela que há afirmações identitárias que fogem a esse esquema, consubstanciadas em espaços de deliberação coletiva. Isto é, permanecem espaços fora da alçada do imperador, que remetem à antiga res publica, mas são tidos como imagens efêmeras.

Ao tempo em que Tácito escreve, após o período de guerras civis subsequentes à morte de Nero, talvez Roma aparecesse como mais inextricavelmente ligada ao princeps, e, portanto, nosso historiador visse como anômala a existência de resquícios da cidade-Estado clássica. Mas isso não significa que outras identidades ligadas a esse aspecto persistissem, sugerindo outras formas de ordenação. 